\title{
Trends of population-based breast cancer survival in Germany and the US: Decreasing discrepancies, but persistent survival gap of elderly patients in Germany
}

Bernd Holleczek ${ }^{1,2^{*}}$ and Hermann Brenner ${ }^{1}$

\begin{abstract}
Background: Studies have revealed both higher cancer survival in the US than in Germany and substantial improvement of cancer survival in the past in these countries. This population-based study aims at comparing most recent 5-year relative survival of breast cancer patients and preceding trends in both countries.

Methods: Women with a first invasive breast cancer diagnosed and followed up between 1988 and 2008 from Germany and the US (utilizing data from the Saarland Cancer Registry and the Surveillance, Epidemiology, and End Results Program, respectively) were included. Period analysis was used to derive most up-to-date 5-year relative survival and preceding survival trends according to age and stage.

Results: Since 1993, age standardized relative survival has steadily improved in Germany and the US to $83 \%$ and $88 \%$, respectively. In the period 2005-08, relative survival of localized cancer was above $97 \%$ in both countries, and $79 \%$ and $83 \%$ for locally/regionally spread breast cancer, respectively. Prognosis of metastasized disease has remained very poor overall, with improvement essentially being restricted to younger patients. The proportion of patients diagnosed with localized breast cancer was consistently higher in the US. If adjusted for stage, the differences in relative survival between both countries diminished over time and eventually disappeared.

Conclusions: Similar survival is now observed in both countries for patients below the age of 70 years, but in Germany survival is still much lower for elderly patients. The observed trends point to treatment advances as a major cause for improved survival. However, substantial differences in mammography usage existed between both countries and might probably also account for the observed differences (to a lesser extent, also differences in health care systems, and delivery of cancer care). Encouraging, survival of breast cancer patients has improved in Germany to a much greater extent than in the US, albeit the persisting survival gap for elderly patients in Germany requires particular attention by researchers, public health authorities, and clinicians.
\end{abstract}

Keywords: Female breast cancer, Survival, Population-based, Trends, Germany, United States

\footnotetext{
* Correspondence: b.holleczek@dkfz-heidelberg.de

1 Division of Clinical Epidemiology and Aging Research, German Cancer Research Center, Im Neuenheimer Feld 581, 69120 Heidelberg, Germany ${ }^{2}$ Saarland Cancer Registry, Präsident Baltz-Straße 5, 66119 Saarbrücken, Germany
}

\section{Ciomed Central}

(c) 2012 Holleczek and Brenner; licensee BioMed Central Ltd. This is an Open Access article distributed under the terms of the Creative Commons Attribution License (http://creativecommons.org/licenses/by/2.0), which permits unrestricted use, distribution, and reproduction in any medium, provided the original work is properly cited. 


\section{Background}

Population-based studies have shown a decrease in breast cancer (BRC) mortality during the past two decades in Germany and the US [1-3] primarily attributed to early detection activities and advances in cancer treatment $[4,5]$ and demonstrated ongoing and substantial improvement of long-term survival of BRC patients [6-8]. Studies have also revealed higher BRC survival in the US than in Germany and other European countries [9-12].

Prolongation of cancer survival may have two principal causes: firstly anticipation of tumour diagnosis or even overdiagnosis by early detection and secondly increased survival due to improved effectiveness of cancer treatment. The time gained if a cancer is diagnosed earlier in a pre symptomatic stage due to screening is called lead time and artificially increases survival time. By itself, early detection does not affect the course of the disease. Therefore, screening requires treatment administered earlier to be effective and to postpone the death of the patient.

Overdiagnosis results from detection of malignant lesions that would never have progressed and presented clinically during the patient's lifetime and survival analyses yield too optimistic estimates due to the inclusion of these non fatal cancers.

Therefore, comparative studies of population-based cancer survival should particularly take into account differences in stage distribution and early detection activities, to understand underlying mechanisms of observed trends over time or differences between populations.

Up to now, available comparative population-based studies on BRC survival were often limited as they provided survival trends stratified by age only (e.g. $[6,7,9]$ ) or reported stage-stratified survival only for singular calendar years $[10,11]$.

A recently published study reported trends of BRC survival by age and stage in Germany [13]. This paper aims at comparing most recent 5-year survival of female BRC patients and preceding trends in Germany and the US by age and stage and discussing the results in the context of observed trends of BRC incidence and mortality, and available data on the implementation and usage of mammography screening and advances in BRC treatment in these countries in the past.

\section{Methods}

Database

For Germany, data from the population-based Saarland Cancer Registry were used. The registry covers the federal state of Saarland, Germany, with approximately 1.04 million residents in 2006 and operates since the beginning of the 1970s. Cancer notification is mandatory by law. The registry obtains notifications from pathology laboratories, hospitals, radiotherapy departments, outpatient clinics, and general practitioners. The completeness of case ascertainment is estimated above $95 \%[14,15]$.

The database from Saarland included 16,014 women aged 15 years or older diagnosed with invasive BRC (ICD-10 code: C50) between 1988 and 2008 (irrespective of previous primary cancers of other sites). Patients with a previous primary malignant tumour of the breast were excluded.

Mortality follow-up based on death certificates was available until end of 2008. Linkage with population registries was additionally performed for all patients assumed alive end of 2008 to identify patients lost to follow-up. Patients having migrated out of the Saarland region contributed survival time until removal. Patients for whom linkage with population registries was not possible (e.g. due to erroneous patient identifiers) were classified as "no follow-up available" and excluded from the analyses.

For the US, data from the Surveillance, Epidemiology, and End Results Program (SEER) were used and included the SEER-9 registries (states of Connecticut, Iowa, New Mexico, Utah, Hawaii, metropolitan regions of San Francisco-Oakland, Detroit, Atlanta, and Seattle Puget Sound area) from 1988 with extension to the SEER-13 registries (Alaska, regions of San JoseMonterey, Los Angeles and Rural Georgia) from 1992 until 2008, covering a population of approximately 41.2 million residents in 2004-08 [16]. The survival analyses included 460,049 BRC patients based on criteria as above. Mortality follow-up was available until end of 2008.

The following data items were used: month and year of diagnosis, age at diagnosis, $\mathrm{T}$ classification, stage (categories: 'localized': T1-3N0M0 tumours; 'local/regional spread': T4M0 and N + M0 tumours; 'distant metastasis': any M1 tumours; unknown extent), basis of diagnosis, month and year of end of follow-up and vital status. Stage was classified according to summary stage reported by the registries or TNM information [17-19]. Clinical extent was used if no pathologic stage was available. For age-specific analyses, three age categories were used: $15-49,50-69$, and 70+ years. Patients with tumours notified from a death certificate only (DCO) were excluded from survival analyses, as were patients for whom no follow-up was available (Saarland only).

Additionally, incidence data of invasive and in situ BRC (ICD-10 codes: C50 and D05), mortality data (ICD10 codes: C50), and population data were used from the registries.

The data used for this study are routinely collected by cancer registries according to state legislation for the purpose of monitoring cancer incidence, mortality, and outcomes and the anonymized data were used according to the respective provisions for the use of research data. 


\section{Statistical analyses}

Age-standardized rates (ASR) and truncated agestandardized rates (TASR) per 100,000 person years using the 2000 US standard population [20] were calculated for BRC incidence and mortality for successive calendar periods of four years between 1989 and 2008 in Germany and the US (all races combined). To account for differences in the registration of multiple primaries, for incidence estimation of invasive and in situ BRC, only the first cancer of the respective tumour type was considered.

A description of the BRC patients with regard to age, $\mathrm{T}$ classification, stage, basis of diagnosis, and DCO notification was provided for intervals of four calendar years between 1989 and 2008 .

Relative survival (RS) which quantifies excess mortality due to the cancer (capturing both direct and indirect mortality) was derived as ratio of observed survival and expected survival for these persons derived from life tables of the underlying populations with respect to sex, age and calendar time (race was also considered for US patients) [21]. The Ederer II method was used to derive expected survival [22].

Life tables for Saarland were calculated for intervals of 5 years since 1990 from mortality and population data for single ages provided by the state statistical office (further details may be found elsewhere [13]). Region- and race-specific life tables for the US were derived from mortality and population data included the SEER database $[23,24]$ for intervals of five calendar years since 1993 using the Elandt-Johnson method [25,26]. Racespecific life tables were either provided for white, black, and other races (three regions), white and races other than white (eight regions), and all races combined (two regions), according to the populations and numbers of deaths [27].

Period analysis was used to obtain most up-to-date estimates of RS. In addition to right censoring, observations are left truncated at the beginning of a calendar period [28]. Extensive empirical evaluation has shown that period estimates closely predict survival observed for the patients diagnosed in the respective calendar period [28-31]. In case of ongoing improvement, period analysis provides survival predictions as up-to-date as possible.

Period estimates of 5-year RS were derived for subsequent calendar periods of four years between 1993 and 2008. To avoid potential artefacts when combining classical cohort based estimates derived for calendar periods with complete follow-up and period estimates for the most recent calendar period, the period approach was continuously used for the entire study period.

To test for linear trend in RS over time, model based period analysis was employed. Poisson regression models for relative survival were fitted modelling the logarithm of the excess number of deaths with a linear predictor of follow-up year (categorical), age group (categorical) and calendar period (numerical), incorporating the logarithm of person time as offset [32]. A significance level of 0.05 (based on a two sided Wald test) was applied.

Besides crude survival, age standardized survival was derived as weighted average of age group-specific survival based on weights from the International Cancer Survival Standards (ICSS) [33]. Throughout the text, age standardized estimates are presented as overall survival. For both countries, stage information and $\mathrm{T}$ classification were reasonably complete $(>70 \%)$ after 1988 . Stage mix-adjusted survival was calculated using the stage distribution of the US patients diagnosed between 1988 and 2008. Standard errors were based on Greenwoods method [34]. The R Language and Environment for Statistical Computing (release 2.11.1; R Foundation for Statistical Computing, Vienna, 2011) and the add-on package 'periodR' (release 1.0-5) [35] were used for data preparation and analysis.

\section{Results}

Table 1 shows trends of BRC incidence and mortality in Germany and the US. At the beginning of the 1990s, age standardized incidence of invasive BRC was higher in the US than in Germany but converged due to a decrease in the US among women aged 70+ years and an increase in Germany among women aged 50+ years to 113 and 111 new cases per 100,000, respectively, in 2005-08. Median age at diagnosis was lower in the US than in Germany (60 and 65 years, respectively).

Age standardized incidence of in situ BRC was about four-fold in the US compared to Germany (ASR: 30.3 vs. 8.5, respectively, in 2005-08). In the US, incidence among women aged 50+ years was similar and 5-fold compared to younger patients (TASR increased to 79.7 and 76.6 vs. 16.7, respectively, in 2005-08). In Germany, the incidence approximately tripled among patients aged 50-69 years (TASR: 22.6) and doubled among the other age groups (TASR: 5.8 and 14.9, respectively).

During the study period, a decrease of BRC mortality was observed in the US across all age categories (ASR: minus $28 \%$ to 23.1 in 2005-08), whereas in Germany mortality slightly decreased only among patients below 70 years of age but increased among older ones (ASR remained virtually unchanged: $-3 \%$ to 30.4 ).

Table 2 presents characteristics of the included patients. The number of women diagnosed during each calendar period of four years has continuously increased. Most recently, the proportion of patients below 70 years of age was somewhat higher in the US than in Germany (71.5\% vs. 65.6\%, respectively). From 1989 through 2008, summary stage was available for $97.2 \%$ of the patients from the US, and for $81.6 \%$ of the German patients. The 
Table 1 Breast cancer incidence and mortality in Germany and the US

\begin{tabular}{|c|c|c|c|c|c|c|c|c|c|c|c|}
\hline & & \multicolumn{5}{|c|}{ Germany (Saarland) } & \multicolumn{5}{|c|}{ US (SEER 9/13 regions) $^{b}$} \\
\hline & & $1989-92$ & 1993-96 & $1997-00$ & 2001-04 & $2005-08$ & $1989-92$ & 1993-96 & $1997-00$ & 2001-04 & 2005-08 \\
\hline \multirow[t]{5}{*}{ incidence of invasive BRC } & crude rate & 115.7 & 128.8 & 140.7 & 153.2 & 162.9 & 118.2 & 115.8 & 124.3 & 120.0 & 118.7 \\
\hline & $\overline{\mathrm{ASR}^{a}}$ & 91.5 & 99.8 & 106.5 & 108.9 & 111.6 & 123.5 & 122.1 & 127.6 & 119.1 & 113.2 \\
\hline & 15-49 (TASR $\left.{ }^{\mathrm{a}}\right)$ & 56.1 & 56.2 & 59.1 & 53.5 & 57.5 & 60.7 & 57.1 & 58.1 & 57.2 & 57.7 \\
\hline & 50-69 (TASR $\left.{ }^{a}\right)$ & 194.9 & 230.2 & 259.7 & 278.6 & 286.6 & 286.0 & 295.1 & 316.0 & 294.0 & 275.5 \\
\hline & $\overline{70+\left(\text { TASR }^{\mathrm{a}}\right)}$ & 293.1 & 311.9 & 310.2 & 329.2 & 320.6 & 433.5 & 419.4 & 431.6 & 388.3 & 358.9 \\
\hline \multirow[t]{5}{*}{ incidence of in situ BRC } & crude rate & 4.3 & 5.8 & 8.3 & 10.8 & 11.4 & 17.2 & 19.6 & 27.2 & 29.4 & 31.6 \\
\hline & $\overline{\mathrm{ASR}^{a}}$ & 3.8 & 4.9 & 6.7 & 8.4 & 8.5 & 18.6 & 21.1 & 28.3 & 29.4 & 30.3 \\
\hline & 15-49 (TASR $\left.{ }^{a}\right)$ & 3.2 & 4.0 & 4.3 & 6.0 & 5.8 & 11.4 & 11.3 & 14.6 & 15.1 & 16.7 \\
\hline & 50-69 (TASR $\left.{ }^{\mathrm{a}}\right)$ & 7.9 & 11.9 & 19.8 & 23.4 & 22.6 & 47.9 & 57.0 & 77.2 & 80.7 & 79.7 \\
\hline & $70+\left(\right.$ TASR $\left.^{\text {a }}\right)$ & 7.7 & 7.7 & 9.6 & 11.7 & 14.9 & 42.7 & 52.5 & 72.1 & 74.3 & 76.6 \\
\hline \multirow[t]{5}{*}{ BRC mortality } & crude rate & 44.1 & 47.4 & 50.3 & 48.2 & 49.3 & 30.0 & 28.6 & 26.0 & 24.9 & 24.7 \\
\hline & $\overline{\mathrm{ASR}^{\mathrm{a}}}$ & 33.4 & 34.2 & 34.7 & 31.9 & 30.4 & 31.9 & 29.7 & 26.2 & 24.2 & 23.1 \\
\hline & 15-49 (TASR $\left.{ }^{a}\right)$ & 13.2 & 12.5 & 11.7 & 8.8 & 7.1 & 11.0 & 9.7 & 8.3 & 7.4 & 7.0 \\
\hline & 50-69 (TASR $\left.{ }^{a}\right)$ & 73.0 & 75.2 & 74.9 & 73.0 & 66.1 & 72.2 & 65.9 & 57.5 & 52.3 & 48.8 \\
\hline & $70+\left(\right.$ TASR $\left.^{a}\right)$ & 143.7 & 152.2 & 162.0 & 152.2 & 159.0 & 141.3 & 137.1 & 124.0 & 117.8 & 114.2 \\
\hline
\end{tabular}

Incidence of invasive and in situ BRC (ICD-10 codes: C50/D05) and BRC mortality (ICD-10 code: C50) of women in Germany (Saarland) and the US (SEER 9/13 regions) between 1989 and 2008 .

BRC: breast cancer; ASR: age standardized rate; TASR: truncated age standardized rate; rates given as new cases/deaths per 100,000; for incidence, only the first tumour of the respective type was considered; ${ }^{a}$ the US2000 standard population was used for standardization; ${ }^{b}$ the coverage of SEER program was extended from 9 to 13 registries in 1992

proportion of patients with T1 tumours and localized disease was continuously lower in Saarland than in the US $(44.8 \%$ and $49.7 \%$ vs. $60.6 \%$ and $63.1 \%$, respectively, in 2005-08). Almost all diagnoses were based on microscopic examinations $(97.2 \%$ and $99.0 \%$, respectively, in 2005-08). In the study period, the overall proportions of DCO notified BRC were $2.5 \%$ in Germany and $0.6 \%$ in the US, respectively.

Trends of 5-year RS between 1993 and 2008 stratified by age group and stage are given in Table 3. Since 1993, overall age-standardized 5-year RS has steadily improved in both countries. Survival was much higher in the US than in Germany. However, the increase in 5-year RS was stronger in Germany $(+10.3 \%$ units to $82.5 \%$ vs. $+3.9 \%$ units to $88.1 \%$ in the US, respectively; p-values: $<0.001$ ), and the pre existing gap between both countries has diminished.

In Germany, survival of patients aged 70+ years did not improve to the same extent as survival of younger patients $(+5.6 \%$ units to $74.9 \%$ vs. $+13.5 \%$ units to $88.4 \%$ in 2005-08; p-values: 0.026 and $<0.001$, respectively). In the US, survival of elderly patients improved to a lesser extent (+2.1\% units to $85.7 \%$ vs. $+5.3 \%$ to $89.7 \%$; p-values: 0.001 and $<0.001$, respectively). As a result, a difference of about $11 \%$ units persisted in 5-year RS of elderly patients between Germany and the US.

Age standardized 5-year RS of localized BRC was $98.7 \%$ in Germany and $97.3 \%$ in the US in 2005-08.
Five-year RS of BRC with local or regional spread was $78.6 \%$ and $82.8 \%$, respectively. If distant sites were already involved at diagnosis time, 5-year RS was $23.7 \%$ and $26.7 \%$ in both countries, respectively.

Since 1993, most improvement of age standardized 5-year RS was observed in Germany for locally/regionally spread BRC, followed by localized disease $(+14.6 \%$ units and $+7.3 \%$ units, respectively; p-values: $<0.001)$. At the same time, improvement of survival of US patients who already had much better prognosis in 1993-96, was less pronounced $(+7.6 \%$ units and $+1.6 \%$ units, respectively; p-values: <0.001) and the gap in 5-year RS between both countries reduced to $4.2 \%$ units and $1.4 \%$ units in $2005-$ 08, respectively. Survival of distant BRC improved by $3.3 \%$ units (p-value: 0.106 ) in Germany and by $6.5 \%$ units in the US (p-value: <0.001).

Part of the overall survival differences between Germany and the US resulted from a higher proportion of patients with less advanced BRC in the US. Adjustment for stage mix reduced survival differences between both countries. In 2005-08, these differences eventually had disappeared (87.9\% and $88.1 \%$, respectively).

Differences in most recent stage-specific 5-year RS and preceding trends between patients aged $>=70$ years and younger ones were varying. Survival of patients with localized BRC was equally high among elderly and younger patients (in 2005-08, it was $96.6 \%$ vs. $97.8 \%$ and $97.4 \%$ vs. $97.2 \%$, respectively, in Germany and the 
Table 2 Characteristics of included breast cancer patients

\begin{tabular}{|c|c|c|c|c|c|c|c|c|c|c|c|}
\hline \multirow{2}{*}{\multicolumn{2}{|c|}{ Category }} & \multicolumn{2}{|c|}{ 1989-1992 } & \multicolumn{2}{|c|}{ 1993-1996 } & \multicolumn{2}{|c|}{$1997-2000$} & \multicolumn{2}{|c|}{ 2001-2004 } & \multicolumn{2}{|c|}{$2005-2008$} \\
\hline & & $n$ & $\%$ & $\mathrm{n}$ & $\%$ & $\mathrm{n}$ & $\%$ & $\mathbf{n}$ & $\%$ & $\mathrm{n}$ & $\%$ \\
\hline & & \multicolumn{10}{|c|}{ Germany (Saarland) } \\
\hline overall & & 2,564 & & 2,877 & & 3,118 & & 3,354 & & 3,494 & \\
\hline \multirow[t]{3}{*}{ age } & $15-49$ years & 514 & 20.0 & 537 & 18.7 & 637 & 20.4 & 594 & 17.7 & 640 & 18.3 \\
\hline & 50-69 years & 1,179 & 46.0 & 1,322 & 46.0 & 1,418 & 45.5 & 1,591 & 47.4 & 1,653 & 47.3 \\
\hline & $>=70$ years & 871 & 34.0 & 1,018 & 35.4 & 1,063 & 34.1 & 1,169 & 34.9 & 1,201 & 34.4 \\
\hline \multirow[t]{4}{*}{ stage } & available & 1,811 & 70.6 & 2,353 & 81.8 & 2,665 & 85.5 & 2,898 & 86.4 & 2,839 & 81.3 \\
\hline & localized $^{a}$ & 694 & 38.3 & 1,043 & 44.3 & 1,260 & 47.3 & 1,448 & 50.0 & 1,411 & 49.7 \\
\hline & local/regional spread ${ }^{a}$ & 912 & 50.4 & 1,082 & 46.0 & 1,143 & 42.9 & 1,179 & 40.7 & 1,186 & 41.8 \\
\hline & distant metastasis $^{a}$ & 205 & 11.3 & 228 & 9.7 & 262 & 9.8 & 271 & 9.4 & 242 & 8.5 \\
\hline \multirow[t]{4}{*}{ tumour size } & available & 2,013 & 78.5 & 2,513 & 87.3 & 2,872 & 92.1 & 3,120 & 93.0 & 3,127 & 89.5 \\
\hline & $\mathrm{T} 1^{\mathrm{a}}$ & 661 & 32.8 & 921 & 36.6 & 1,126 & 39.2 & 1,384 & 44.4 & 1,402 & 44.8 \\
\hline & $\mathrm{T} 2^{\mathrm{a}}$ & 953 & 47.3 & 1,116 & 44.4 & 1,249 & 43.5 & 1,249 & 40.0 & 1,293 & 41.3 \\
\hline & $\mathrm{T} 3 / 4^{\mathrm{a}}$ & 399 & 19.8 & 476 & 18.9 & 497 & 17.3 & 487 & 15.6 & 432 & 13.8 \\
\hline \multicolumn{2}{|c|}{ microscopic confirmation } & 2,418 & 94.3 & 2,761 & 96.0 & 3,018 & 96.8 & 3,251 & 96.9 & 3,397 & 97.2 \\
\hline \multicolumn{2}{|c|}{ death certificate only notified } & 82 & 3.2 & 62 & 2.2 & 52 & 1.7 & 59 & 1.8 & 79 & 2.3 \\
\hline \multicolumn{2}{|c|}{ no follow-up available } & 64 & 2.5 & 43 & 1.5 & 79 & 2.5 & 67 & 2.0 & 49 & 1.4 \\
\hline & & \multicolumn{10}{|c|}{ US (SEER 9/13 regions ${ }^{b}$ ) } \\
\hline \multicolumn{2}{|l|}{ overall } & 64,556 & & 87,228 & & 97,713 & & 97,579 & & 98,857 & \\
\hline \multirow[t]{3}{*}{ age } & $15-49$ years & 15,314 & 23.7 & 21,103 & 24.2 & 23,124 & 23.7 & 23,592 & 24.2 & 23,731 & 24.0 \\
\hline & $50-69$ years & 27,007 & 41.8 & 36,641 & 42.0 & 42,501 & 43.5 & 44,147 & 45.2 & 46,914 & 47.5 \\
\hline & $>=70$ years & 22,235 & 34.4 & 29,484 & 33.8 & 32,088 & 32.8 & 29,840 & 30.6 & 28,212 & 28.5 \\
\hline \multirow[t]{4}{*}{ stage } & available & 62,016 & 96.1 & 84,078 & 96.4 & 94,920 & 97.1 & 95,510 & 97.9 & 97,094 & 98.2 \\
\hline & localized $^{a}$ & 39,075 & 63.0 & 54,468 & 64.8 & 61,062 & 64.3 & 59,715 & 62.5 & 61,235 & 63.1 \\
\hline & local/regional spread ${ }^{a}$ & 19,186 & 30.9 & 24,684 & 29.4 & 28,472 & 30.0 & 30,169 & 31.6 & 29,843 & 30.7 \\
\hline & distant metastasis $^{\text {a }}$ & 3,755 & 6.1 & 4,926 & 5.9 & 5,386 & 5.7 & 5,626 & 5.9 & 6,016 & 6.2 \\
\hline \multirow[t]{4}{*}{ tumour size } & available & 53,027 & 82.1 & 73,352 & 84.1 & 85,692 & 87.7 & 87,682 & 89.9 & 93,254 & 94.3 \\
\hline & $\mathrm{T} 1^{\mathrm{a}}$ & 33,518 & 63.2 & 47,364 & 64.6 & 55,847 & 65.2 & 56,038 & 63.9 & 56,522 & 60.6 \\
\hline & $\mathrm{T} 2^{\mathrm{a}}$ & 14,848 & 28.0 & 20,080 & 27.4 & 22,746 & 26.5 & 24,007 & 27.4 & 27,088 & 29.0 \\
\hline & $T 3 / 4^{a}$ & 4,661 & 8.8 & 5,908 & 8.1 & 7,099 & 8.3 & 7,637 & 8.7 & 9,644 & 10.3 \\
\hline \multicolumn{2}{|c|}{ microscopic confirmation } & 63,443 & 98.3 & 85,855 & 98.4 & 96,357 & 98.6 & 96,364 & 98.8 & 97,831 & 99.0 \\
\hline \multicolumn{2}{|c|}{ death certificate only notified } & 394 & 0.6 & 497 & 0.6 & 602 & 0.6 & 554 & 0.6 & 479 & 0.5 \\
\hline
\end{tabular}

Characteristics of female breast cancer patients (ICD-10 code: C50) from Germany (Saarland) and the US (SEER 9/13 regions) diagnosed between 1989 and 2008.

${ }^{a}$ proportion among patients with available stage/T classification; ${ }^{b}$ the coverage of SEER program was extended from 9 to 13 registries in 1992.

US). Survival of patients with locally/regionally spread BRC improved less and was much lower for elderly patients in both countries (in 2005-08, it was $70.8 \%$ vs. $85.1 \%$ and $77.5 \%$ vs. $87.0 \%$, respectively). Among patients with metastasized BRC, improvements were highest for patients $<50$ years of age $(+18.2 \%$ units and $+11.9 \%$ units to $29.6 \%$ and $38.8 \%$, respectively; p-values: 0.029 and $<0.001$ ), but no substantial improvement was seen for elderly patients (changes of $-1.8 \%$ units and $+2.1 \%$ units to $15.3 \%$ and $19.4 \%$, respectively; p-values: 0.712 and 0.045$)$.

Age standardized 5-year RS of BRC patients with unknown or missing stage information was varying in both countries. In Germany, it was about $80 \%$ during the study period. In the US, it varied slightly between $55 \%$ and 58\% between 1993 and 2004, but dropped to 45\% in the most recent calendar period.

\section{Discussion}

In this study, most recent 5-year RS of female BRC patients from Germany and the US and preceding trends were analyzed using data from the population-based Saarland Cancer Registry and the SEER 9/13 registries. In 2005-08, age standardized 5-year RS was $82.5 \%$ and 88.1\% for all stages combined, $98.7 \%$ and $97.3 \%$ for localized BRC, $78.6 \%$ and $82.8 \%$ for BRC with local or regional spread and $23.7 \%$ and $26.7 \%$ for tumours with 
Table 3 Five-year relative survival of breast cancer patients by age and stage

\begin{tabular}{|c|c|c|c|c|c|c|c|c|c|c|c|c|c|c|c|c|c|c|c|c|c|}
\hline \multirow[t]{3}{*}{ stage } & & \multicolumn{10}{|c|}{ Germany (Saarland) } & \multicolumn{10}{|c|}{ US (SEER 9/13 regions ${ }^{a}$ ) } \\
\hline & & \multicolumn{2}{|c|}{$1993-96$} & \multicolumn{2}{|c|}{$1997-00$} & \multicolumn{2}{|c|}{ 2001-04 } & \multicolumn{2}{|c|}{ 2005-08 } & \multirow[t]{2}{*}{$\Delta$} & \multirow[t]{2}{*}{ p-value } & \multicolumn{2}{|c|}{$1993-96$} & \multicolumn{2}{|c|}{$1997-00$} & \multicolumn{2}{|c|}{$2001-04$} & \multicolumn{2}{|c|}{ 2005-08 } & \multirow[t]{2}{*}{$\Delta$} & \multirow[t]{2}{*}{ p-value } \\
\hline & & RS & SE & RS & SE & RS & SE & RS & SE & & & RS & SE & RS & SE & RS & SE & RS & SE & & \\
\hline \multirow[t]{7}{*}{ overall } & crude & 73.0 & 1.1 & 77.1 & 1.0 & 80.1 & 0.9 & 84.2 & 0.9 & 11.2 & $<0.001$ & 84.1 & 0.2 & 86.3 & 0.2 & 88.2 & 0.1 & 88.6 & 0.1 & 4.5 & $<0.001$ \\
\hline & age std $^{b}$ & 72.2 & 1.3 & 76.3 & 1.2 & 79.0 & 1.1 & 82.5 & 1.0 & 10.3 & $<0.001$ & 84.2 & 0.2 & 86.3 & 0.2 & 88.2 & 0.2 & 88.1 & 0.2 & 3.9 & $<0.001$ \\
\hline & stage mix std ${ }^{c}$ & 78.8 & 1.1 & 82.3 & 0.9 & 85.3 & 0.8 & 87.9 & 0.7 & 9.1 & $<0.001$ & 84.1 & 0.2 & 85.7 & 0.1 & 87.7 & 0.1 & 88.1 & 0.1 & 4.0 & $<0.001$ \\
\hline & $15-49$ years & 75.4 & 2.0 & 78.6 & 1.8 & 83.9 & 1.6 & 87.7 & 1.4 & 12.3 & $<0.001$ & 82.8 & 0.3 & 85.2 & 0.3 & 87.3 & 0.2 & 89.2 & 0.2 & 6.4 & $<0.001$ \\
\hline & $50-69$ years & 74.7 & 1.4 & 79.1 & 1.3 & 81.7 & 1.1 & 88.6 & 1.0 & 14.0 & $<0.001$ & 85.4 & 0.2 & 87.5 & 0.2 & 89.8 & 0.2 & 90.0 & 0.2 & 4.7 & $<0.001$ \\
\hline & $15-69$ years & 74.9 & 1.2 & 78.9 & 1.0 & 82.3 & 0.9 & 88.4 & 0.8 & 13.5 & $<0.001$ & 84.4 & 0.2 & 86.7 & 0.2 & 88.9 & 0.1 & 89.7 & 0.1 & 5.3 & $<0.001$ \\
\hline & $>=70$ & 69.3 & 2.4 & 73.6 & 2.2 & 75.1 & 2.1 & 74.9 & 2.1 & 5.6 & 0.026 & 83.6 & 0.4 & 85.5 & 0.4 & 86.5 & 0.4 & 85.7 & 0.4 & 2.1 & 0.001 \\
\hline \multirow[t]{8}{*}{ localized } & crude & 90.7 & 1.5 & 93.3 & 1.2 & 96.0 & 1.0 & 97.5 & 0.9 & 6.8 & 0.002 & 95.4 & 0.2 & 96.1 & 0.2 & 97.0 & 0.2 & 97.2 & 0.1 & 1.8 & $<0.001$ \\
\hline & e std ${ }^{b}$ & 91.4 & 2.4 & 94.5 & 1.9 & 97.4 & 1.6 & 98.7 & 1.4 & 7.3 & $<0.001$ & 95.7 & 0.2 & 96.3 & 0.2 & 97.3 & 0.2 & 97.3 & 0.2 & 1.6 & $<0.001$ \\
\hline & $15-49$ years & 86.9 & 2.5 & 92.3 & 1.9 & 93.1 & 1.6 & 95.3 & 1.4 & 8.4 & 0.011 & 93.6 & 0.3 & 94.1 & 0.2 & 95.4 & 0.2 & 96.3 & 0.2 & 2.7 & $<0.001$ \\
\hline & $50-69$ years & 91.7 & 1.8 & 91.6 & 1.5 & 95.4 & 1.2 & 98.7 & 0.9 & 7.0 & 0.001 & 95.4 & 0.2 & 96.4 & 0.2 & 97.4 & 0.2 & 97.6 & 0.2 & 2.2 & $<0.001$ \\
\hline & $15-69$ years & 90.1 & 1.5 & 91.8 & 1.2 & 94.7 & 0.9 & 97.8 & 0.7 & 7.7 & $<0.001$ & 94.8 & 0.2 & 95.6 & 0.1 & 96.8 & 0.1 & 97.2 & 0.1 & 2.4 & $<0.00$ \\
\hline & $>=70$ years & 93.2 & 4.6 & 98.3 & 3.5 & 99.9 & 2.9 & 96.6 & 2.9 & 3.4 & 0.555 & 96.7 & 0.5 & 97.0 & 0.4 & 97.5 & 0.4 & 97.4 & 0.4 & 0.7 & 0.290 \\
\hline & $\mathrm{T} 1$ age std $^{\mathrm{b}}$ & 97.3 & 4.0 & 99.3 & 2.9 & 99.5 & 2.4 & 104.1 & 1.8 & 6.8 & - & 98.8 & 0.3 & 99.5 & 0.2 & 99.9 & 0.2 & 100.4 & 0.2 & 1.7 & - \\
\hline & 3 age std $^{b}$ & 89.4 & 3.7 & 92.1 & 2.9 & 93.9 & 2.4 & 92.1 & 2.4 & 2.7 & 0.110 & 86.3 & 0.6 & 87.0 & 0.5 & 89.7 & 0.5 & 89.3 & 0.5 & 3.0 & $<0.00$ \\
\hline \multirow{8}{*}{$\begin{array}{l}\text { local/regional } \\
\text { spread }\end{array}$} & crude & 65.2 & 1.8 & 70.9 & 1.7 & 76.4 & 1.5 & 81.1 & 1.5 & 15.9 & $<0.001$ & 75.8 & 0.4 & 79.0 & 0.3 & 83.3 & 0.3 & 85.0 & 0.3 & 9.2 & $<0.001$ \\
\hline & age std $^{b}$ & 64.0 & 2.2 & 70.3 & 2.0 & 74.8 & 1.9 & 78.6 & 1.8 & 14.6 & $<0.001$ & 75.1 & 0.4 & 77.5 & 0.4 & 81.7 & 0.4 & 82.8 & 0.4 & 7.6 & $<0.001$ \\
\hline & $15-49$ years & 70.7 & 3.4 & 71.4 & 3.1 & 81.1 & 2.7 & 82.6 & 2.6 & 11.9 & 0.004 & 75.5 & 0.6 & 80.2 & 0.5 & 83.5 & 0.4 & 86.8 & 0.4 & 11.3 & $<0.001$ \\
\hline & 50-69 years & 65.3 & 2.5 & 72.2 & 2.2 & 77.6 & 1.9 & 86.2 & 1.7 & 20.8 & $<0.001$ & 78.1 & 0.5 & 80.6 & 0.4 & 86.3 & 0.3 & 87.1 & 0.3 & 9.1 & $<0.001$ \\
\hline & $15-69$ years & 66.9 & 2.0 & 71.9 & 1.8 & 78.6 & 1.6 & 85.1 & 1.4 & 18.2 & $<0.001$ & 76.9 & 0.4 & 80.4 & 0.3 & 85.2 & 0.3 & 87.0 & 0.2 & 10.0 & $<0.001$ \\
\hline & $>=70$ years & 61.1 & 4.0 & 68.7 & 3.7 & 70.5 & 3.7 & 70.8 & 3.6 & 9.7 & 0.084 & 72.4 & 0.9 & 74.3 & 0.8 & 76.7 & 0.8 & 77.5 & 0.8 & 5.1 & $<0.001$ \\
\hline & $\mathrm{T1} / 2$ age std $^{\mathrm{b}}$ & 73.0 & 3.1 & 79.3 & 2.7 & 84.4 & 2.4 & 85.6 & 2.2 & 12.6 & $<0.001$ & 81.4 & 0.5 & 83.6 & 0.5 & 87.7 & 0.4 & 88.1 & 0.4 & 6.7 & $<0.001$ \\
\hline & T3/4 age std ${ }^{b}$ & 47.1 & 3.6 & 52.3 & 3.5 & 56.2 & 3.4 & 64.3 & 3.2 & 17.2 & $<0.001$ & 64.3 & 1.0 & 68.1 & 0.9 & 71.7 & 0.8 & 68.8 & 0.8 & 4.5 & 0.00 \\
\hline \multirow{6}{*}{$\begin{array}{l}\text { distant } \\
\text { metastasis }\end{array}$} & crude & 20.2 & 3.0 & 21.9 & 3.0 & 20.1 & 2.6 & 23.0 & 3.0 & 2.8 & 0.111 & 21.2 & 0.7 & 24.1 & 0.7 & 27.2 & 0.7 & 29.2 & 0.7 & 7.9 & $<0.001$ \\
\hline & age std $^{\text {b }}$ & 20.3 & 3.2 & 22.1 & 3.0 & 19.0 & 2.6 & 23.7 & 3.0 & 3.3 & 0.106 & 20.2 & 0.7 & 22.5 & 0.7 & 25.2 & 0.7 & 26.7 & 0.7 & 6.5 & $<0.001$ \\
\hline & $15-49$ years & 11.5 & 5.8 & 17.9 & 8.9 & 26.9 & 7.6 & 29.6 & 9.1 & 18.2 & 0.029 & 26.8 & 1.5 & 31.5 & 1.4 & 34.5 & 1.4 & 38.8 & 31.4 & 11.9 & $<0.001$ \\
\hline & 50-69 years & 25.3 & 4.4 & 24.7 & 4.4 & 23.6 & 4.0 & 29.1 & 4.6 & 3.8 & 0.237 & 21.3 & 1.0 & 24.4 & 1.0 & 29.0 & 1.0 & 30.5 & 1.0 & 9.2 & $<0.001$ \\
\hline & 15-69 years & 22.0 & 3.7 & 23.9 & 3.9 & 24.5 & 3.5 & 28.5 & 4.1 & 6.5 & 0.058 & 23.2 & 0.9 & 26.9 & 0.8 & 30.9 & 0.8 & 33.2 & 0.8 & 10.0 & $<0.001$ \\
\hline & $>=70$ years & 17.2 & 5.9 & 19.3 & 4.7 & 13.3 & 3.7 & 15.3 & 4.2 & -1.9 & 0.712 & 17.4 & 1.1 & 18.2 & 1.1 & 19.0 & 1.1 & 19.4 & 1.1 & 2.1 & 0.045 \\
\hline \multirow{2}{*}{$\begin{array}{l}\text { unknown } \\
\text { stage }\end{array}$} & crude & 78.4 & 2.5 & 81.3 & 2.8 & 77.0 & 3.5 & 81.4 & 2.8 & 3.0 & 0.381 & 55.2 & 1.2 & 57.7 & 1.2 & 55.0 & 1.4 & 43.5 & 1.5 & -11.7 & $<0.001$ \\
\hline & age std ${ }^{b}$ & 78.7 & 2.5 & 82.1 & 2.7 & 77.6 & 3.2 & 82.7 & 2.5 & 4.0 & 0.084 & 55.6 & 1.3 & 59.0 & 1.2 & 56.1 & 1.5 & 45.2 & 1.6 & -10.4 & $<0.001$ \\
\hline
\end{tabular}

Five-year relative survival of female patients with invasive breast cancer (ICD-10 code: C50) from Germany (Saarland) and the US (SEER 9/13 regions) by age and stage for successive calendar periods.

RS: relative survival (period estimate) in \%; SE: standard error; std: standardized; $\Delta$ : difference of RS between $2005-08$ and $1993-96$ in $\%$ units; ${ }^{a}$ the coverage of SEER program was extended from 9 to 13 registries in 1992; ${ }^{b}$ using weights from the International Cancer Survival Standards [33]; ${ }^{c}$ weights derived from the SEER patients diagnosed 1988-2008.

involvement of distant sites at diagnosis, respectively, in Germany and the US.

During the study period, most overall improvement of 5-year RS was observed for locally/regionally spread $\mathrm{BRC}$, followed by localized tumours. As increases were more pronounced among German patients, the existing discrepancies between the two countries have decreased over time. Among patients with metastasized BRC, substantial improvement was seen only for patients below
50 years of age. The differences in stage-adjusted survival have entirely disappeared over time.

In Germany, 5-year RS and its improvement over time were inferior for patients aged 70+ years resulting both in an increased age gradient in Germany and prevailing differences in 5-year RS of elderly patients between the two countries.

The health care systems differ fundamentally in both countries. In Germany, health care is decentralized with 
private practice physicians and mostly public hospitals providing most ambulatory and impatient care. In 2007, $95.7 \%$ of the population had health insurance coverage through public or private health insurance [36]. In the US, health care facilities largely belong to the private sector and health insurance by private or government health insurance schemes covered $84.7 \%$ of the population in 2006/07 [37]. Both countries have a high standard of living and spend more than $10 \%$ of their gross domestic product into health care [38].

In the US, organized breast cancer screening was introduced (with regional differences and different types of programs) at the beginning of the 1990s [39]. Widespread use of mammography has been reported. The proportion of women aged 50 years or older reporting to have had a mammogram within the past two years increased between 1987 and 2005 from $27.4 \%$ to $68.4 \%$ $[40,41]$.

In Germany, implementation of organized mammography screening started only recently in 2003. The quality-assured programme offers women aged 50 to 69 years a screening mammography every two years. Prior to its introduction in 2006, only opportunistic screening was available in Saarland [42]. In 2002-04, $45.3 \%$ of women aged 55 years or older residing in Saarland reported to have had a mammography within the last two years (unpublished data from the populationbased ESTHER cohort study in Saarland [43,44]). For $2007-08$, a proportion of $53 \%$ of eligible women participating in the organized screening was reported $[45,46]$.

In the US, organized mammography screening started earlier and was intensely used even among younger and elderly women. Data on the usage of opportunistic mammography from Germany prior to the introduction of the organized screening are sparse. Based on the data available, it may be assumed that mammography usage and screening was much lower in Germany during the study among all age categories.

Higher usage of mammography in the US compared to Germany is well reflected in the presented incidence data. Higher proportions of earlier stages and a fourfold incidence of in situ tumours in the US correlate with the differences in the adoption and intensity of mammography screening [47-49].

Diagnosis of in situ lesions of the breast is usually based on a microscopic examination and basis for a notification from a pathology laboratory. According to the registration practises of the SEER registries and the Saarland Cancer registry, we assumed the observed differences in incidence of in situ tumours to represent differences in screening activities (or prevalence of risk factors) rather than differences in case ascertainment.

The observed drop in incidence of invasive BRC in the US after the year 2000 may reflect the change in the prescription of hormone replacement therapy [50,51], whereas the implementation of mammography screening probably interacts with this effect in Germany. However, differences and changes in the prevalence of 'traditional' risk factors have also to be kept in mind. BRC mortality started to decline at the end of the 1980s in the US and approximately ten years later in Germany (data not shown).

To account for overestimation of survival of patients with screen detected cancers we performed analyses stratified by age and stage. This at least partly allowed combining patients with comparable stages with regard to begin of follow up, even if lead time effects remain present within all stages. Furthermore, beneficial effects of screening have even been demonstrated between clinically and screening detected tumours of same stage [52].

The introduction of organized screening in Germany at the end of the study period, the higher intensity of mammography usage in the US on the one hand, and a much higher increase in 5-year RS in Germany on the other hand, support the presumption of advances in the treatment of the disease and adoption of treatment recommendations as a major cause of the remarkable gain in survival in Germany and advanced disease during the study period. However, increased early detection surely has interfered with these developments. As an observational study, it cannot fully resolve the contributions of improved treatment and screening as underlying reasons of the striking increase of 5-year RS in Germany.

Major advances in BRC treatment during the past 20 years included improved staging (e.g. more sensitive medical imaging and sentinel node dissection), propagation of breast conserving surgery and adjuvant radiotherapy for effective local treatment of early stage disease and new agents for chemotherapy and antiestrogen treatment, and targeted biologic agents. Treatment according to consensus recommendations and tailored to the patient's individual risk and a wider range of treatment options has increased the number of patients eligible for cancer-specific treatments.

For elderly patients, co-morbidity and differences in the delivery of cancer care are well documented (e.g. delay in seeking cancer care and influences of co-morbidity on selection of cancer treatments [53], lower likelihood of receiving adjuvant radiotherapy or chemotherapy compared to younger patients, even after adjustment for co-morbidity and extent of disease [54-57]) and may explain inferior 5-year RS and its less pronounced increase [58-60].

The widespread use of mammography among elderly women in the US (the proportion of women aged 75+ years reporting to have had a mammogram within the 
last two years increased from $17.3 \%$ to $54.7 \%$ between 1987 and 2005) [41] most likely exaggerated the increase in survival over time among these patients and may have partly concealed existing differences in age-specific survival in the US, as lead time effects and overdiagnosis particularly strongly affect survival estimates of a population segment with increased (age-related) mortality. Nevertheless, the observed differences in the survival of elderly patients between both countries - particularly pronounced in locally/regionally advanced disease - may point to possible limitations and hesitant delivery of care to elderly patients in Germany.

In the interpretation of the findings, a number of limitations and strengths should be considered. A major limitation is the restricted availability of clinical information. Although rather crude, the used staging scheme allowed survival estimation for three rather distinct groups of BRC patients with regard to available treatment options. Tumour stage and $\mathrm{T}$ classification were sufficiently complete.

The proportions of patients with missing stage were much higher in Germany than in the US. Survival of German patients with unknown stage was comparable to overall survival. Survival of US patients with unknown stage was much lower, possibly due to higher proportions of patients with clinical cancers of more advanced stage.

Further determinants beyond age and tumour stage, e.g. information about administered treatments, socioeconomic status, or co-morbidity were not available. Neither was the method of first detection to consider screening effects as well as lead time, length time and overdiagnosis [5,61].

The included registries operate as established registries with high levels of completeness of case ascertainment and follow-up [14-16,62]. So far, no other populationbased cancer registry from Germany may provide trend data as presented in this article. Even if it constitutes only $1.3 \%$ of the overall population, the Saarland region is well representative for Germany and its health care system and the size of its population allowed analyses stratified by age and stage as most fundamental prognostic factors with sufficient precision. However, when interpreting point estimates of 5-year RS we also considered the corresponding trends, particularly for strata with small numbers of subjects.

The 17 registries currently included in the SEER programme cover approximately one fourth of the US population. The covered regions are regarded reasonably representative for the US, although the population is categorized as somewhat more urban, with less unemployment, higher education and higher smoking prevalence $[16,63,64]$. One has to keep in mind, that such population differences might also have affected participation in mammography screening and access to cancer care of the included SEER populations $[65,66]$.

To avoid artefacts in the most recent survival trends due to the inclusion of the four registries which joined the SEER programme in 2000 (California regions, Kentucky, Louisiana and New Jersey), we restricted the analyses to the SEER 13 regions. Additionally performed analyses of these four regions provided almost identical survival estimates for 2005-08 (differences of overall, age- and stage-specific estimates ranging between 0.2 and $1.7 \%$ units; data not shown).

The validity of cancer diagnoses may be considered high, as almost all tumours were microscopically confirmed. When interpreting stage-specific survival, stage migration (a shift of classification towards more advanced stages due to increased sensitivity and improved accuracy of diagnostic procedures) has to be kept in mind [67]. Interim revisions of the BRC classification schemes [17-19] might be of little effect only with regard to the used clinical stages.

In addition to comparability issues of included patients and tumour stages, the completeness of follow-up and estimation of background mortality is crucial in survival comparisons.

The proportions of DCO notified cases were rather small in the used databases. Under such circumstances, the effects of the exclusion of DCO cases from the analysis or a possible correction for DCO cases are expected to be very small according to recent work [68].

RS as a measure for survival in the hypothetical situation where the disease under study would be the only cause of death (denoted as net survival) is dependent on the general population mortality (the composition of cancer patients under follow-up changes over time with regard to demographic characteristics) [69]. To account for such dependencies and minimize effects we provided and used age standardized estimates for inter country comparison.

The strategy of using the period analysis approach for all subsequent calendar periods aimed at deriving most up-to-date estimates (even in case of ongoing improvement) and consistent use of methodology to prevent potential artefacts in the derived time trends due to a mixture of classical cohort based and period survival estimates.

The observed trends of RS and corresponding p-values were considered on their own and carefully interpreted in the light of further empirical observations. Therefore, we did not account for multiple testing despite the overall number of performed statistical tests for significance [70].

Follow-up was almost complete for both the German and the US patients. It has been shown, that national life tables may not adequately describe overall mortality of a subpopulation and result in biased estimates of RS (e.g. 
for the US, use of national life tables overestimates SEER survival estimates) [71]. Therefore, region- and racespecific life tables were derived for the analyses.

As the aim of population-based survival analyses is to provide a picture of the overall control of cancer in the societies compared, we did not restrict the analyses to any ethnic subpopulation (e.g. inclusion of white US patients only). Otherwise this would result in an inappropriate selective exclusion of socio-economically less privileged patients in one of the countries compared. Additional analyses were performed with a restriction to white US patients only. The effects of such an exclusion were generally small (estimates of crude, age standardized and stage adjusted survival estimates of whites were $1.5 \%$ units above estimates of all races combined), but considerable effects were observed for younger patients and more advanced stages (e.g. survival of whites aged 15-49 years with metastasized BRC was $4.5 \%$ units higher than estimates of all races combined; data not shown).

\section{Conclusions}

The findings may have several important implications. Transatlantic differences in 5-year RS and tumour related excess mortality of BRC patients revealed in previous studies have continuously decreased in recent years.

The observed survival trends point to advances in BRC treatment as a major cause for the gain in prognosis in both countries. Differences in early detection activities and effects due to lead time and overdiagnosis further account for the observed differences.

Whereas most overall improvement was observed for patients with locally or regionally advanced disease, prognosis of patients with distant sites involved at diagnosis is still limited. Despite interim advances in the availability of (increasingly costly) treatment options for patients with metastasized disease, only some moderate overall improvement has been observed for these patients during the past 15 years. The implementation of mammography screening in Germany in recent years will hopefully further reduce the numbers of breast tumours with advanced stage.

Particularly for Germany, this study indicated striking deficits in cancer survival of elderly patients. The gap in cancer related mortality between elderly patients and younger ones in Germany has even increased over time. Inequalities in the access to and provision of cancer care of elderly patients need to be jointly focussed on in future by cancer research, health care policy, and the medical community.

\section{Abbreviations}

BRC: Breast cancer; SEER: Surveillance, Epidemiology, and End Results Program; ASR: Age-standardized rate; TASR: Truncated age-standardized rate;
DCO: Death certificate only; RS: Relative survival; ICSS: International Cancer Survival Standards.

\section{Competing interests}

The authors declare that they have no competing interests.

\section{Authors' contributions}

This study was designed by $\mathrm{BH}$ and $\mathrm{HB}$. $\mathrm{BH}$ prepared and managed the dataset and analyzed the data. $\mathrm{BH}$ and $\mathrm{HB}$ provided interpretation of the results. $\mathrm{BH}$ drafted the manuscript and $\mathrm{HB}$ critically reviewed and revised the draft. Both authors have approved the final version of the manuscript.

\section{Acknowledgements}

This work was supported in part by the German Cancer Aid (Deutsche Krebshilfe; grants 70-3166-Br5, 108257 and 108761). The German Cancer Aid had no role in the design, the data collection, the analysis, the interpretation of the results, the writing of the manuscript, or in the decision to submit the manuscript.

Received: 17 June 2012 Accepted: 18 July 2012

Published: 28 July 2012

\section{References}

1. Botha $J$, Bray F, Sankila R, Parkin DM: Breast cancer incidence and mortality trends in 16 European countries. Eur J Cancer 2003, 39:1718-1729.

2. Autier P, Boniol M, La Vecchia C, Vatten L, Gavin A, Hery C, Heanue M: Disparities in breast cancer mortality trends between 30 European countries: retrospective trend analysis of WHO mortality database. BMJ 2010, 341:c3620.

3. Jemal A, Center MM, DeSantis C, Ward EM: Global patterns of cancer incidence and mortality rates and trends. Cancer Epidemiol Biomarkers Prev 2010, 19:1893-1907.

4. Berry DA, Cronin KA, Plevritis SK, Fryback DG, Clarke L, Zelen M, Mandelblatt JS, Yakovlev AY, Habbema JD, Feuer EJ: Effect of screening and adjuvant therapy on mortality from breast cancer. $N$ Engl J Med 2005, 353:1784-1792.

5. Elmore JG, Armstrong K, Lehman CD, Fletcher SW: Screening for breast cancer. JAMA 2005, 293:1245-1256.

6. Verdecchia A, Guzzinati S, Francisci S, De Angelis R, Bray F, Allemani C, Tavilla A, Santaquilani M, Sant M: Survival trends in European cancer patients diagnosed from 1988 to 1999. Eur J Cancer 2009, 45:1042-1066.

7. Gondos A, Bray F, Hakulinen T, Brenner H: Trends in cancer survival in 11 European populations from 1990 to 2009: a model-based analysis. Ann Oncol 2009, 20:564-573.

8. SEER Cancer Statistics Review, 1975-2008 (based on November 2010 SEER data submission, posted to the SEER web site). [http://seer.cancer.gov/csr/ 1975_2008/index.html]

9. Rosso S, Gondos A, Zanetti R, Bray F, Zakelj M, Zagar T, Smailyte G, Ponti A, Brewster DH, Voogd AC, et al: Up-to-date estimates of breast cancer survival for the years 2000-2004 in 11 European countries: the role of screening and a comparison with data from the United States. Eur J Cancer 2010, 46:3351-3357.

10. Gondos A, Arndt V, Holleczek B, Stegmaier C, Ziegler H, Brenner H: Cancer survival in Germany and the United States at the beginning of the 21st century: an up-to-date comparison by period analysis. Int J Cancer 2007, 121:395-400.

11. Sant M, Allemani C, Berrino F, Coleman MP, Aareleid T, Chaplain G, Coebergh JW, Colonna M, Crosignani P, Danzon A, et al: Breast carcinoma survival in Europe and the United States. Cancer 2004, 100:715-722.

12. Coleman MP, Quaresma M, Berrino F, Lutz JM, De Angelis R, Capocaccia R, Baili P, Rachet B, Gatta G, Hakulinen T, et al: Cancer survival in five continents: a worldwide population-based study (CONCORD). Lancet Oncol 2008, 9:730-756.

13. Holleczek B, Arndt V, Stegmaier C, Brenner H: Trends in breast cancer survival in Germany from 1976 to 2008-A period analysis by age and stage. Cancer Epidemiol 2011, 35:399-406.

14. Brenner H, Stegmaier C, Ziegler H: Estimating completeness of cancer registration: an empirical evaluation of the two source capture-recapture approach in Germany. J Epidemiol Community Health 1995, 49:426-430. 
15. Robert Koch Institute, Association of Population-based Cancer Registries in Germany (Ed): Cancer in Germany 2003-2004. Incidence and Trends. Berlin: Robert Koch Institute; 2008.

16. Surveillance, Epidemiology, and End Results (SEER) Program: Research Data 1973-2008 (released April 2011, based on the November 2010 submission). Bethesda MD: National Cancer Institute, DCCPS, Surveillance Research Program, Cancer Statistics Branch; 2011.

17. Hermanek P, Sobin LH (Eds): TNM Classification of Malignant Tumours. 4th edition. Berlin: Springer; 1987

18. Sobin LH, Wittekind C (Eds): UICC TNM Classification of Malignant Tumours. 5th edition. New York: Wiley-Liss; 1997.

19. Sobin LH, Wittekind C (Eds): TNM Classification of Malignant Tumours. 6th edition. New York: Wiley-Liss; 2002.

20. Klein RJ, Schoenborn CA: Age adjustment using the 2000 projected U.S. population. Healthy People 2010. Stat Notes 2001, 20:1-10.

21. Ederer F, Axtell LM, Cutler SJ: The relative survival rate: a statistical methodology. Natl Cancer Inst Monogr 1961, 6:101-121.

22. Ederer $\mathrm{F}$, Heise $\mathrm{H}$ : Instructions to IBM 650 programmers in processing survival computations. Bethesda (MD): National Cancer Institute; 1959.

23. Surveillance, Epidemiology, and End Results (SEER) Program: SEER*Stat Database: Mortality - All COD, Aggregated With State, Total U.S. (1969-2008). Underlying mortality data provided by NCHS. Bethesda MD: National Cancer Institute, DCCPS, Surveillance Research Program, Cancer Statistics Branch; 2011 (www.cdc.gov/nchs).

24. Surveillance, Epidemiology, and End Results (SEER) Program: SEER*Stat Database: Populations - Total U.S. (1969-2009). Linked to country attributes Total U.S. (1969-2009)). Bethesda, MD: National Cancer Institute, DCCPS, Surveillance Research Program, Cancer Statistics Branch; 2011.

25. Elandt-Johnson R, Johnson N: Survival Models and Data Analysis (Wiley Series in Probability and Mathematical Statistics). Indianapolis: John Wiley \& Sons; 1980.

26. Baili P, Micheli A, Montanari A, Capocaccia R: Comparison of Four Methods for Estimating Complete Life Tables from Abridged Life Tables Using Mortality Data Supplied to EUROCARE-3. Math Popul Stud 2005, 12:183-198.

27. National Center for Health Statistics: U.S. decennial life tables for 1989-91, vol 1, no. 2, methodology of the national and State life tables. Hyattsville, Maryland; 1998.

28. Brenner H, Gefeller O, Hakulinen T: Period analysis for 'up-to-date' cancer survival data: theory, empirical evaluation, computational realisation and applications. Eur J Cancer 2004, 40:326-335.

29. Talback M, Stenbeck M, Rosen M: Up-to-date long-term survival of cance patients: an evaluation of period analysis on Swedish Cancer Registry data. Eur J Cancer 2004, 40:1361-1372

30. Brenner $\mathrm{H}$, Hakulinen $\mathrm{T}$ : Up-to-date long-term survival curves of patients with cancer by period analysis. J Clin Oncol 2002, 20:826-832.

31. Brenner $H$, Soderman $B$, Hakulinen $T$ : Use of period analysis for providing more up-to-date estimates of long-term survival rates: empirical evaluation among 370,000 cancer patients in Finland. Int J Epidemiol 2002, 31:456-462

32. Brenner $\mathrm{H}$, Hakulinen $\mathrm{T}$ : Up-to-date and precise estimates of cancer patient survival: model-based period analysis. Am J Epidemiol 2006, 164:689-696.

33. Corazziari I, Quinn M, Capocaccia R: Standard cancer patient population for age standardising survival ratios. Eur J Cancer 2004, 40:2307-2316.

34. Greenwood M: A report on the natural duration of cancer. HM Stationery Office: Reports on Public Health and Medical Subjects. London; 1926

35. Holleczek B, Gondos A, Brenner H: periodR - an R package to calculate long-term cancer survival estimates using period analysis. Methods Int Med 2009, 48:123-128.

36. European Community Health Indicators (ECHI). [http://www.gbe-bund.de/ gbe10/abrechnung.prc_abr_test_logon? p uid $=$ gast\&p_aid $=38176193 \& p$ sprache $=E \& p \_$knoten $\left.=T R 80000\right]$

37. DeNavas-Walt C, Proctor BD, Smith JC: Current Population Reports, P60-235, Income, Poverty, and Health InsuranceCoverage in the United States: 2007. Washington, DC: U.S. Census Bureau; 2008.

38. Anderson GF, Hussey PS, Frogner BK, Waters HR: Health spending in the United States and the rest of the industrialized world. Health Aff (Millwood) 2005, 24:903-914.

39. Shapiro S, Coleman EA, Broeders M, Codd M, de Koning H, Fracheboud J, Moss S, Paci E, Stachenko S, Ballard-Barbash R: Breast cancer screening programmes in 22 countries: current policies, administration and guidelines. International Breast Cancer Screening Network (IBSN) and the European Network of Pilot Projects for Breast Cancer Screening. Int J Epidemiol 1998, 27:735-742

40. Swan J, Breen N, Coates RJ, Rimer BK, Lee NC: Progress in cancer screening practices in the United States: results from the 2000 National Health Interview Survey. Cancer 2003, 97:1528-1540.

41. Use of Mammography Among Women 40 Years of Age and over. [http:// www.cdc.gov/nchs/health_policy/mammography.htm]

42. Becker N: Epidemiological aspects of cancer screening in Germany. J Cancer Res Clin Oncol 2003, 129:691-702.

43. Low M, Stegmaier C, Ziegler $H$, Rothenbacher D, Brenner $H$ : Epidemiological investigations of the chances of preventing, recognizing early and optimally treating chronic diseases in an elderly population (ESTHER study). Dtsch Med Wochenschr 2004, 129:2643-2647.

44. Raum E, Rothenbacher D, Low M, Stegmaier C, Ziegler H, Brenner H: Changes of cardiovascular risk factors and their implications in subsequent birth cohorts of older adults in Germany: a life course approach. Eur J Cardiovasc Prev Rehabil 2007, 14:809-814.

45. Malek D, Rabe P: Evaluationsbericht 2008-2009. Ergebnisse des Mammographie-Screening-Programms in Deutschland. Berlin: Kooperationsgemeinschaft Mammographie; 2012.

46. Dreier M, Borutta B, Toppich J, Bitzer EM, Walter U: Mammography and Cervical Cancer Screening - A Systematic Review about Women's Knowledge, Attitudes and Participation in Germany. Gesundheitswesen 2011, doi:10.1055/s-0031-1286271.

47. Barchielli A, Federico M, De Lisi V, Bucchi L, Ferretti S, Paci E, Ponti A, Buiatti $E$ : In situ breast cancer: incidence trend and organised screening programmes in Italy. Eur J Cancer 2005, 41:1045-1050.

48. Ernster VL, Barclay J, Kerlikowske K, Grady D, Henderson C: Incidence of and treatment for ductal carcinoma in situ of the breast. JAMA 1996, 275:913-918.

49. Virnig BA, Tuttle TM, Shamliyan T, Kane RL: Ductal carcinoma in situ of the breast: a systematic review of incidence, treatment, and outcomes. $J$ Nat/ Cancer Inst 2010, 102:170-178.

50. Glass AG, Lacey JV Jr, Carreon JD, Hoover RN: Breast cancer incidence, 1980-2006: combined roles of menopausal hormone therapy, screening mammography, and estrogen receptor status. J Natl Cancer Inst 2007, 99:1152-1161.

51. Ravdin PM, Cronin KA, Howlader N, Berg CD, Chlebowski RT, Feuer EJ, Edwards BK, Berry DA: The decrease in breast-cancer incidence in 2003 in the United States. N Engl J Med 2007, 356:1670-1674.

52. Wishart GC, Greenberg DC, Britton PD, Chou P, Brown CH, Purushotham $A D$, Duffy SW: Screen-detected vs symptomatic breast cancer: is improved survival due to stage migration alone? Br J Cancer 2008, 98:1741-1744

53. Janssen-Heijnen ML, Maas HA, Houterman S, Lemmens VE, Rutten HJ, Coebergh JW: Comorbidity in older surgical cancer patients: influence on patient care and outcome. Eur J Cancer 2007, 43:2179-2193.

54. Bouchardy C, Rapiti E, Fioretta G, Laissue P, Neyroud-Caspar I, Schafer P, Kurtz J, Sappino AP, Vlastos G: Undertreatment strongly decreases prognosis of breast cancer in elderly women. J Clin Oncol 2003, 21:3580-3587.

55. Lavelle K, Todd C, Moran A, Howell A, Bundred N, Campbell M: Nonstandard management of breast cancer increases with age in the UK: a population based cohort of women $>$ or $=65$ years. Br J Cancer 2007, 96:1197-1203.

56. Passage KJ, McCarthy NJ: Critical review of the management of earlystage breast cancer in elderly women. Intern Med J 2007, 37:181-189.

57. Hancke K, Denkinger MD, Konig J, Kurzeder C, Wockel A, Herr D, Blettner M, Kreienberg R: Standard treatment of female patients with breast cancer decreases substantially for women aged 70 years and older: a German clinical cohort study. Ann Oncol, 21:748-753.

58. Sant M, Allemani C, Santaquilani M, Knijn A, Marchesi F, Capocaccia R: EUROCARE-4. Survival of cancer patients diagnosed in 1995-1999. Results and commentary. Eur J Cancer 2009, 45:931-991.

59. Vercelli M, Capocaccia R, Quaglia A, Casella C, Puppo A, Coebergh JW: Relative survival in elderly European cancer patients: evidence for health care inequalities. The EUROCARE Working Group. Crit Rev Oncol Hematol 2000, 35:161-179.

60. Gondos A, Holleczek B, Arndt V, Stegmaier C, Ziegler H, Brenner H: Trends in population-based cancer survival in Germany: to what extent does progress reach older patients? Ann Oncol 2007, 18:1253-1259. 
61. Day NE: Overdiagnosis and breast cancer screening. Breast Cancer Res 2005, 7:228-229.

62. Harlan LC, Hankey BF: The surveillance, epidemiology, and end-results program database as a resource for conducting descriptive epidemiologic and clinical studies. J Clin Oncol 2003, 21:2232-2233.

63. Merrill RM, Dearden KA: How representative are the surveillance, epidemiology, and end results (SEER) program cancer data of the United States? Cancer Causes Control 2004, 15:1027-1034.

64. Wingo PA, Jamison PM, Hiatt RA, Weir HK, Gargiullo PM, Hutton M, Lee NC, Hall HI: Building the infrastructure for nationwide cancer surveillance and control-a comparison between the National Program of Cancer Registries (NPCR) and the Surveillance, Epidemiology, and End Results (SEER) Program (United States). Cancer Causes Control 2003, 14:175-193.

65. Frey CM, McMillen MM, Cowan CD, Horm JW, Kessler LG: Representativeness of the surveillance, epidemiology, and end results program data: recent trends in cancer mortality rates. J Natl Cancer Inst 1992, 84:872-877.

66. Nattinger AB, McAuliffe TL, Schapira MM: Generalizability of the surveillance, epidemiology, and end results registry population: factors relevant to epidemiologic and health care research. J Clin Epidemiol 1997, 50:939-945.

67. Feinstein AR, Sosin DM, Wells CK: The Will Rogers phenomenon. Stage migration and new diagnostic techniques as a source of misleading statistics for survival in cancer. N Engl J Med 1985, 312:1604-1608.

68. Brenner $\mathrm{H}$, Holleczek B: Deriving valid population-based cancer survival estimates in the presence of nonnegligible proportions of cancers notified by death certificates only. Cancer Epidemiol Biomarkers Prev 2011, 20:2480-2486

69. Perme MP, Stare J, Esteve J: On estimation in relative survival. Biometrics 2012, 68:113-120

70. Rothman KJ: No adjustments are needed for multiple comparisons. Epidemiology 1990, 1:43-46.

71. Baili P, Micheli A, De Angelis R, Weir HK, Francisci S, Santaquilani M, Hakulinen T, Quaresmas M, Coleman MP: Life tables for world-wide comparison of relative survival for cancer (CONCORD study). Tumori 2008, 94:658-668

doi:10.1186/1471-2407-12-317

Cite this article as: Holleczek and Brenner: Trends of population-based breast cancer survival in Germany and the US: Decreasing discrepancies, but persistent survival gap of elderly patients in Germany. BMC Cancer 2012 12:317.

\section{Submit your next manuscript to BioMed Central and take full advantage of:}

- Convenient online submission

- Thorough peer review

- No space constraints or color figure charges

- Immediate publication on acceptance

- Inclusion in PubMed, CAS, Scopus and Google Scholar

- Research which is freely available for redistribution 